cerned with binding $m \mathrm{RNA}$ to ribosomes, which has some of the properties of factor $\mathrm{C}$.

The work reported here confirms the role of ribosome subunits in the initiation of protein synthesis. Several studies have shown that initiation factors promote the formation of a complex $m \mathrm{RNA}-30 S$-initiator $t \mathrm{RNA}^{\mathbf{9 , 1 5 , 2 1 , 2 2}}$ As Nomura has proposed ${ }^{15}$, the non-ambiguous reading of the initiation codon as F-met- $t$ RNAF can be explained by the fact that other $t$ RNA do not bind the $30 S$ ribosome alone. This might be explained by the fact that factor $\mathrm{C}$ does not allow the binding of any other $t \mathrm{RNA}$ but F-met$t$ RNAF (ref. 16), leading to the formation of an initiation complex on the $30 \mathrm{~S}$ subunit the thermostability of which is very close to that of the normal $70 S-m \mathrm{RNA}-t \mathrm{RNA}$ complexes. This initiation complex can then react, in the presence of factor $\mathrm{A}$, with the $50 S$ subunit to form a functional $70 S$ complex*.

The experiments presented here also indicate that factor $\mathrm{B}$ is only concerned with the recognition of at least certain natural $m$ RNAs. This factor has no effect when AUG or poly AUG is used as messenger. $B$ is not required for F-met- $t$ RNA $A_{F}$ binding, but in its absence natural $m$ RNA does not promote the formation of F-methionyl puromycin. This suggests that the initiation codon in $m$ RNA is bound to the ribosome in such a way as to prevent introduction of F-met- $t \mathrm{RNA}_{\mathrm{F}}$ in the donor site if factor $\mathrm{B}$ is absent. The lack of effect of factor B on AUG or TYMV RNA or in the poly $U N$-acetyl-phe- $t$ RNA system may be explained by assuming that with these templates the correct codon can be placed spontaneously in the appropriate ribosomal site.

In vitro synthesis of an active enzyme such as $T 4$ lysozyme ${ }^{13}$ suggests that the ribosomal system is capable of reading with little ambiguity the punctuation on $m$ RNA: that is, a codon AUG or GUG meaning chain initiation can be distinguished from an internal similar codon. One possible interpretation is that secondary structure of the RNA would prevent ribosomes from binding to the internal region of the message, as has been suggested for f2 RNA (ref. 23). Possibly also another mechanism exists involving factor $B$ which appears to be

* The question as to whether factor $\mathrm{C}$ is still present in the $70 \mathrm{~S}$ remains open. Factor $\mathrm{C}$ is not found in naturally occurring $70 \mathrm{~S}$ dimers and it has been suggested that this factor is recycling between the native $30 S^{\prime}$ subunits ${ }^{9-11}$. required only for natural $m \mathrm{RNA}$ known to be translated without errors in the $E$. coli cell-free system. This factor might then conceivably be concerned with the recognition of a nucleotide sequence more complex than AUG or GUG.

This work was supported by grants from the Fonds de Développement de la Recherche Scientifique et Technique, the Commissariat à l'Energie Atomique, the Centre National de la Recherche Scientifique, the Ligue Nationale Française contre le Cancer, the Fondation pour la Recherche Médicale Française and l'Institut National de la Santé et de la Recherche Médicale. We thank Dr W. Salser for his help and Miss B. Bertin for technical assistance.

\section{Received August 2, 1968.}

${ }^{1}$ Marcker, K. A., and Sanger, F., J. Mol. Biol., 8, 835 (1964),

${ }^{2}$ Adams, J. M., and Capecchi, M. R., Proc. US Nat. Acad. Sci., 55, 147 (1966).

${ }^{3}$ Clark, B. F. C., and Marcker, K. A., J. Mol. Biol., 17, 394 (1966).

- Eisenstadt, J. M., and Brawerman, G., Biochemistry, 5, 2777 (1966)

${ }^{5}$ Stanley, W. M., Salas, M., Wahba, A. J., and Ochoa, S., Proc. US Nat. Acad. Sci., 56, 290 (1966)

' Revel, M., and Gros, F., Biochem. Biophys. Res. Commun., 25, 124 (1966).

'Mangiarotti, G., and Schlessinger, D., J. Mol. Biol., 20, 123 (1966).

${ }^{8}$ Kaempfer, R., Meselson, M., and Raskas, M., J. Mol. Biol., 31, 277 (1968).

${ }^{9}$ Eisenstadt, J., and Brawerman, G., Proc. US Nat. Acad. Sci., 58, 1560 (1967).

${ }^{10}$ Revel, M., and Gros, F., Biochem. Biophys. Res. Commun., 27, 12 (1967),

${ }^{11}$ Revel, M., Herzberg, M., Becarevic, A., and Gros, F., J. Mol. Biol., 33, 231 (1968).

12 Babinet, C., Biochem. Biophys, Res, Commun, 26, 639 (1967).

${ }^{13}$ Salser, W., Gesteland, W., and Bolle, M. A., Nature, 215, 588 (1967).

${ }^{14}$ Lucas Lenard, J., and Lipmann, F., Proc. US Nat. Acad. Sci., 57, 1050 (1967).

${ }^{15}$ Nomura, M., and Lowry, C. V., Proc. US Nat. Acad. Sci., 58, 946 (1967). ${ }^{16}$ Grunberg-Manago, M., Revel, M., Dondon, J., Hayes, D., and Gros, F., Bull. Soc. Chim. Biol. (in the press).

18 Bretscher, M. S, and Marcker, K. A., Nature, 211, 380 (1966).

${ }^{18}$ Iwasaki, K., Sabol, S., Wahba, A., and Ochoa, S., Arch. Biochem. Biophys. (in the press).

${ }^{19}$ Maitra, U., and Doubnoff, J., Fed. Proc., 27, 398 (1968).

${ }^{20}$ Brown, J. C., and Doty, P., Biochem. Biophys. Res. Commun., 30, 284 (1968).

${ }^{21}$ Mukundan, N., Hershey, J., Dewey, K., and Thach, R., Nature, 217, 1013 (1968).

${ }^{22}$ Hille, M. B., Miller, M. J., Iwasaki, K., and Wahba, A., Proc. US Nat. Acad. Sci., 58, 1652 (1967).

${ }^{23}$ Lodish, H., J. Mol. Biol. (in the press).

${ }^{24}$ Nirenberg, M., and Leder, P., Science, 145, 1399 (1964).

${ }^{25}$ Leder, P., and Burztyn, H., Biochem. Biophys. Res. Commun., 25, 233 (1966).

\title{
Mechanism of Lymphocyte Transformation induced by Phytohaemagglutinin
}

by

M. J. SIMONS

R. FOWLER

Immunology Section,

Surgical Research Department,

Royal Children's Hospital Research

Foundation

M. G. FITZGERALD

Cytogenetics Laboratory,

Department of Pathology,

Royal Children's Hospital,

Melbourne, Australia

Phytohammagglutinin (PHA) can induce blast transformation of leucocytes in culture ${ }^{1-4}$, but the mechanism and the biological significance of lymphocyte transformation are not yet understood. Studies of the mode of action
The role of phytohaemagglutinin (PHA) determinants and lymphocyte surface reactive sites has been investigated in the lymphocyte transformation phenomenon. Results suggest that the mitogenic moiety of the PHA molecule is closely related to or identical with the antigenic determinant sites, and that some of these PHA antigenic sites are similar to those found amongst the antigenic configuration on the surface of lymphocytes. 
been reviewed ${ }^{5-7}$ and other variables in the quantitation of the response have been delineated ${ }^{8}$. The recovery of morphologically uniform populations of the reactive cell type (small lymphocytes), and the definition of optimal culture conditions which control or eliminate recognized variables, have provided the opportunity for studying the mechanism of the action of PHA by more sensitive and discriminatory techniques.

The different order of magnitude of lymphocyte response to PHA, and the response to antigens to which the lymphocyte donor has been previously sensitized, raise the question as to whether a truly qualitative or only a quantitative difference is involved ${ }^{9}$. The mitogenic action of PHA may differ qualitatively from the secondary response to antigens in vitro ${ }^{10-12}$, or PHA may represent a type of "universal antigen" such that the difference between the response to PHA and to antigens is one of degree rather than of kind $^{18-15}$.

We have investigated the relationships between the antigenic and mitogenic moieties of PHA, and between these moieties and antigenic determinants carried on the surface of lymphocytes.

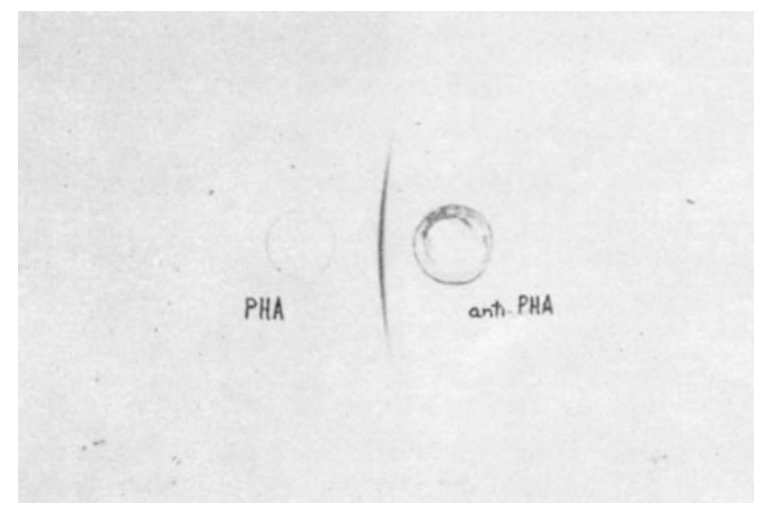

Fig. 1. Immunodiffusion pattern of PHAx13 showing single preeipitin arc.

\section{Preparation and Testing of Antisera}

Anti-PHA antisera. The PHA used throughout was a purified preparation, PHAx13, given by Dr B. A. L. Hurn, Burroughs Wellcome Laboratories, Beckenham, Kent. This material was of limited availability and so antisera against it were prepared in mice by initial intraperitoneal injections of PHA in Freund's adjuvant, followed by booster injections at convenient intervals for 10-12 months. Rabbit anti-PHA antisera (also given by Dr B. A. L. Hurn) were also used.

The presence and titre of precipitating antibodies against PH.A were tested by radial diffusion and by immunoelectrophoretic analysis. In double diffusion in agar only a single band was formed (Fig. 1). Irnmunoclectrophoretic analysis, however, revealed two distinct bands (Fig. 2). The precipitating antibody titre against PHA in the mice antisera reached $1: 32$ with continued immunization. Titres of agglutinating antibodies were determined by the addition of two-fold dilutions of anti-PHA to $2 \mu \mathrm{g}$ of PHA. After incubation for $2 \mathrm{~h}$ at $37^{\circ} \mathrm{C}$ and overnight at $4^{\circ} \mathrm{C}$, a precipitate was formed to a titre of $1: 64$.

Cross reactivity of the anti-PHA antisera with human lymphocytes was sought by first absorbing the antisera with lymphocytes and then testing for residual anti-PHA activity by simple tube agglutination. Following absorption the titre of agglutinating antibody against PHA fell from $1: 64$ to $1: 8$ (Fig. 3 ).

Anti-lymphocyte serum. Anti-lymphocyte serum was prepared in rabbits by initial intramuscular injection of a

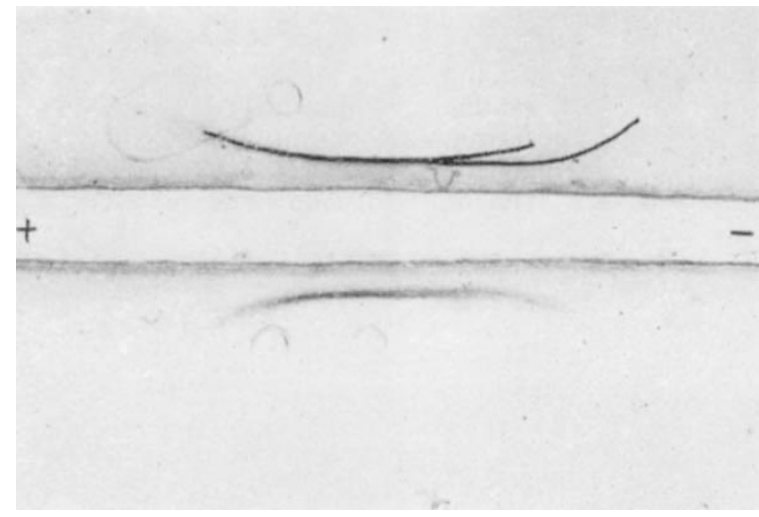

Iig. 2. Immunoelectrophoretic pattern of PHAx13 illustrating two precipitin ares.

saline suspension of lymphocytes in complete Freund's adjuvant followed by intravenous booster injections at convenient intervals. Lymphocytotoxic and lymphoagglutinating antibody activity was tested by the methods of Abaza and Woodruff ${ }^{16}$. Complement was removed from all antisera by heat inactivation at $56^{\circ} \mathrm{C}$ for $30 \mathrm{~min}$ to avoid possible complement dependent cytolysis.

The lymphocytotoxic and lymphoagglutinating titres of the anti-lymphocyte serum were $1: 640$ and $1: 1,280$ respectively. As a result of contaminating red cells in the immunizing cell suspension, high titres of haemagglutinins ( $1: 2,560)$ were produced. These were effectively reduced to a titre of $1: 2$ to $1: 4$ by absorption with washed packed red cells without any detcctable reduction in in vitro anti-lymphocyte activity.

\section{Culture of Lymphocytes}

Highly purified (98-100 per cent) suspensions of small lymphocytes from peripheral blood were obtained by a column separation method, using cotton instead of glass wool, and cultured in conditions established as optimal for maximum response ${ }^{9}$. Lymphocyte response was quantitated by measurement of tritiated thymidine $\left(\mathrm{H}_{3} \mathrm{~T}\right)$ incorporation into newly synthesized DNA. Unstimulated cultures showed negligible DNA synthesis.

Lymphocy te culture experimonts were designed to study, first, the effect of unmodified PHA and lymphocytes together in culture; second, interference with the mitogenic determinant sites of the PHA molecule; and third, interference with lymphocyte membrane reactive sites. Cultures were therefore established to observe: (1) the effect of PHA on normal lymphocytes; (2) the effect of

\section{PHA/anti-PHA}

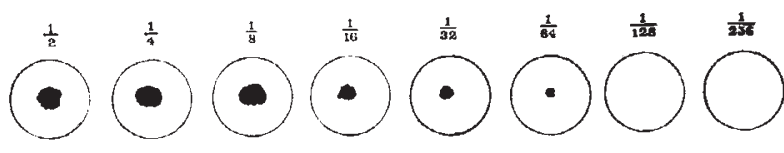

PHA/Absorbed anti-PHA

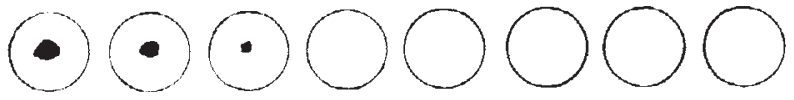

Fig. 3. After absorption of anti-PHA antiserum with human lymphoeytes there is a reduction in titre of anti-PHA antibodies from $1: 64$ 


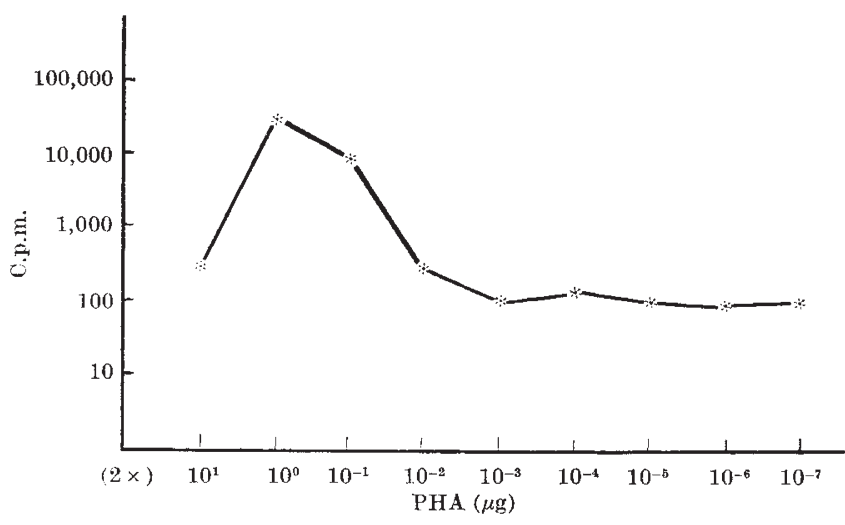

Fig. 4. Effect of PHA concentration. The optimal concentration for maximal responsiveness is $2 \mu \mathrm{g} / 1 \times 10^{6}$ cells.

PHA which had been incubated with (a) anti-PHA and (b) anti-lymphocyte serum, on normal lymphocytes; (3) the effect of PHA on lymphocytes pre-treated with $(a)$ anti-PHA and $(b)$ anti-lymphocyte serum. Unstimulated control cultures, in which the effects of various sources of serum supplement-normal human, mouse and rabbit sera, and indifferent immune mouse and rabbit serawere investigated. The indifferent rabbit immune serum tested was a hyperimmune serum containing high titre agglutinating antibodies against Escherichia coli. The mouse immune serum was raised against tuberculoprotein.

The effect of a variety of doses of PHA on Iymphocyte responsiveness was examined and the dose-response curve established. The optimal concentration of PHA for maximal stimulation was found to be $2 \mu \mathrm{g} / \mathrm{ml}$. (Fig. 4).

The addition of two-fold dilutions of anti-PHA to PHA in tubes resulted in the formation of aggregates to a dilution of $1: 64$. The supernatant obtained after centrifugation of these tubes was added to lymphocytes in culture for $72 \mathrm{~h}$. Fig. 5 shows that the mitogenic activity was absent from those tubes where the antigenantibody agglutination was greatest. There was a proportional relationship between the degree of stimulation and the amount of residual unagglutinated PHA activity. When the washed, insoluble PHA/anti-PHA complexes were resuspended in $0.05 \mathrm{ml}$. of saline and added to lymphocytes in culture, no stimulation was observed.

When two-fold dilutions of anti-lymphocyte serum were incubated with PHA, visible agglutinins were formed to a titre of $1: 128$. When lymphocytes were incubated for $1 \mathrm{~h}$ with anti-lymphocyte serum it was found that the stimulatory effect of PHA was virtually abolished. Again there was a proportional relationship between the antilymphocyte serum dilution and the magnitude of the

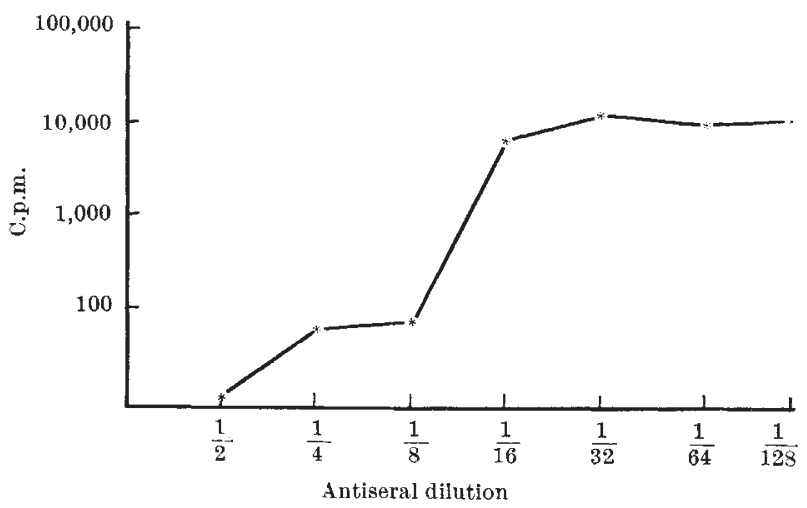

Fig. 5. Effect of PHA after treatment with anti-PHA antisera, showing loss of mitogenic activity at the lower antiseral dilutions. response to PHA (Fig. 6). There is a threshold titre of antilymphocyte serum beyond which there is insufficient antilymphocyte antibody available to inhibit the PHA effect.

Interference with Lymphocyte Surface Reactive Sites

When $0.05 \mathrm{ml}$. of anti-PHA antiserum was incubated for $1 \mathrm{~h}$ with lymphocytes, the antibody activity against PHA was reduced, indicated by a fall in the agglutinating antibody titre (Fig. 3). The anti-PHA remains absorbed to the lymphocytes because, despite three saline washings, these lymphocytes gave a submaximal response to stimulation by PHA (Table 1). When serial dilutions of the anti-PHA antisera were used for absorption it was found that, with progressive dilution, the agglutinin titres approached those of unabsorbed antisera, and the lymphocyte response progressed towards the magnitude given by untreated lymphocytes.

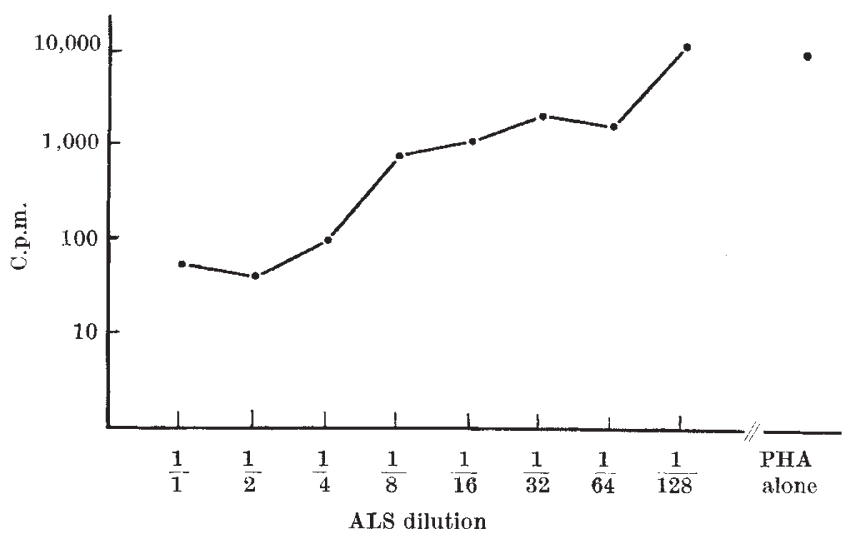

Fig. 6. Effect of PHA after absorption with ALS, again showing loss of mitogenic activity at the lower antiseral dilutions.

Table 1. LYMPHOCYTES ABSORBED WITH ANTI-PHA ANTISERUM SHOW A MARKED REDUCTION IN RESPONSE TO SUBSEQUENT STIMULATION WITH PHA

\begin{tabular}{ccc} 
& \multicolumn{2}{c}{ Cultures (c.p.m.) } \\
Lymphocytes & Control & PHA stimulated \\
Unabsorbed & 86 & 10,120 \\
Absorbed with anti-PHA & 79 & 2,840
\end{tabular}

When lymphocytes were incubated with ten-fold dilutions of anti-lymphocyte serum for $1 \mathrm{~h}$, washed and resuspended in medium containing PHA, an inverse correlation was found between the concentration of antilymphocyte serum and the magnitude of the subsequent PHA response (Fig. 7). This inhibitory effect of antilymphocyte serum was observed with all anti-lymphocyte antisera. When anti-lymphocyte serum alone was incubated with lymphocytes to ten-fold dilutions for $72 \mathrm{~h}$, stimulation occurred in some experiments. This effect varied with both the source of the anti-lymphocyte sera and the time of sampling following repeated immunization. and with small lymphocytes obtained from different, donors.

No stimulation was observed in the $72 \mathrm{~h}$ cultures when normal sera, either human, mouse or rabbit, were used as serum supplements. Both mouse and rabbit hyperimmune sera failed to stimulate lymphocytes and they had no inhibitory effect on the subsequent stimulation by PHA, in contrast to the inhibitory effects of mouse antiPHA and rabbit anti-lymphocyte serum.

\section{Relationship between Antigenic and Mitogenic Moieties}

The relative purity of the PHA we used compared with the crude commercial preparations was revealed by immunodiffusion. Mice immunized with PHA responded by the production of only two demonstrable types of antibodies. Other workers ${ }^{17-19}$ have found up to eight 
separate lines of precipitating antibodies on immunoelectrophoresis of rabbit antiserum prepared against commercial PHA. PHAx13 is a more potent mitogenic agent on a weight for weight basis than commercial PHA (our unpublished results), so several of the antigenic determinants in the crude material cannot be involved in the mitogenic effect. Are the residual antigenic determinants which are responsible for the production of the two types of antibodies seen on immunoelectrophoresis themselves mitogenic or are they quite separate from the mitogenic portions of the molecule?

If there was a relation between the antigenic activity and the mitogenic moiety, it might be expected that blocking of the antigenic determinants with antiserum would result in disappearance of the mitogenic activity. In tubes in which antigen-antibody aggregates were formed, there was negligible or considerably reduced mitogenic activity in the supernatant. Possibly no PHA would be left in the supernatant to act as a stimulant if the formation of the agglutinates involved not just the antigenic components of the PHA macromolecule but removal of the entire molecule from solution. In these circumstances the antigen-antibody complex might still

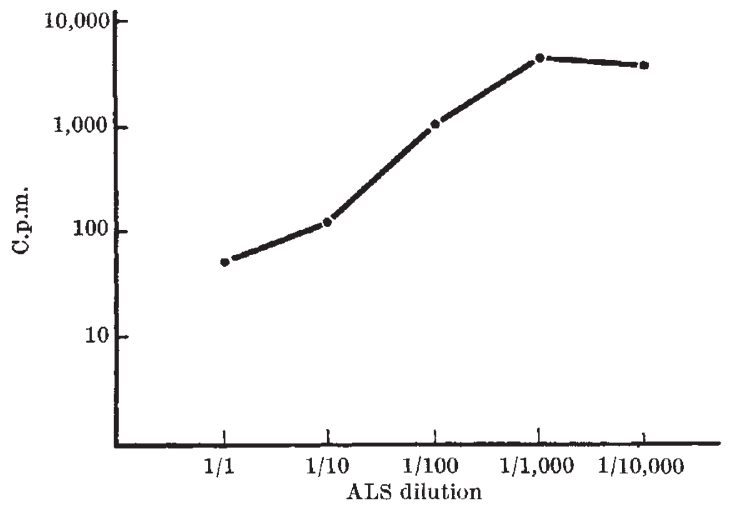

Fig. 7. Effect of PHA on ALS-treated lymphocytes showing inhibition of response at the lower antiseral dilutions.

retain its mitogenic activity. Alternatively, the absence of mitogenic activity from the agglutinate would be evidence for the sharing of antigenic and mitogenic determinant sites.

To test this point the stimulatory activity of the washed agglutinates was assessed. No activity was found in the washed agglutinates, giving support to the hypothesis that the antigenic determinants are closely related to, if not identical with, the mitogenic moiety.

Experiments on the effect of interference with the lymphocyte surface reactive sites derived from an observation made on some cultures that had served as controls. Treatment of lymphocytes with anti-PHA was associated with a diminished response to subsequent exposure to PHA (Table 1). Absorption of anti-PHA on lymphocytes seemed to be a specific event in that the antibody was not removed by triple saline washing. As the titre of anti-PHA was progressively diluted, there was a corresponding diminution of inhibition of the response. This suggests that there is a sharing of the antigenic determinant sites between the PHA molecules responsible for the production of the antisera and the lymphocyte surface antigenic determinants. If sharing takes place, anti-lymphocyte serum should contain antibodies which cross-react with PHA.

\section{Role of Lymphocyte Surface}

The antigenic determinants on the lymphocyte surface which are blocked by the anti-lymphocyte serum could

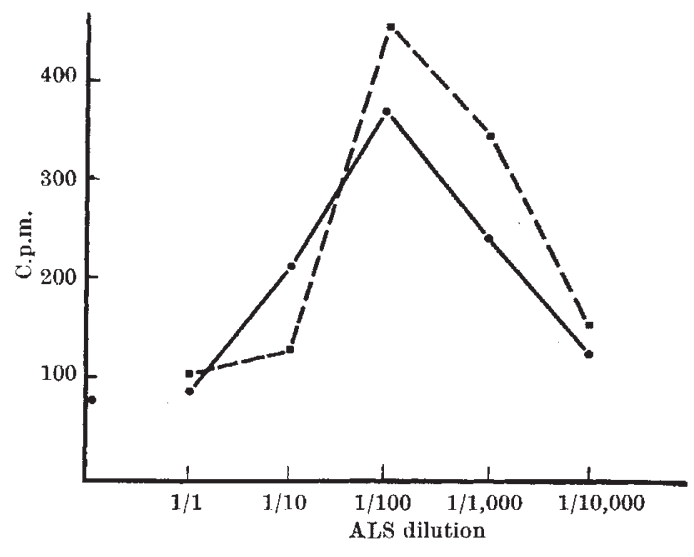

Fig. 8. Effect of ALS alone.

be intimately involved in the mitogenic activity of the PHA. Alternatively, this apparent sharing of determinant sites could be the result of a non-specific steric effect. The presence of anti-lymphocy te antibodies might so completely mask the surface of the lymphocyte that the sites which are important in the PHA response are rendered inaccossible to the appropriate PHA determinants.

In so far as normal serum and indifferent hyperimmune serum exerted no blocking effect, the effects of both antilymphocyte serum and anti-PHA in inhibiting the responsiveness of treated lymphocytes are phenomena specific to these antisera. In contrast to the ineffectiveness of various control sera, in experiments with several anti-immunoglobulin antisera, we have found that equine anti-human $\operatorname{Ig} G$, anti-IgA and anti-IgM antisera have a pronounced inhibitory effect on lymphocyte responsiveness to PHA. The inhibitory effect of these anti-immunoglobulin antisera is reproducible, but, as with anti-lymphoeyte serum, the stimulatory effect is inconstant. Fig. 9 illustrates one experiment in which stimulation was achieved with anti-IgG and anti-IgA, but not with anti-IgM. Stimulation by anti-Iymphocyte serum has been reported ${ }^{10,20,21}$, although an inhibitory effect is a recent observation ${ }^{22,23}$. Stimulation with anti-immunoglobulin antisera and component fractions has been reported in lymphocyte culture systems using sheep lymphocytes ${ }^{24}$, but with human lymphocytes the reports are conflicting ${ }^{25,26}$. Inhibition by anti-immunoglobulin antisera of the PHA response has not been previously reported, although other agents, such as mycoplasma ${ }^{27}$, rubella $^{28}$ and vaccinia (unpublished results of M. J. S. and M. G. F.) viruses, have been shown to interfere with PHA stimulation.

Both anti-lymphocyte serum and anti-immunoglobulin antisera can inhibit the response to PHA in one set of

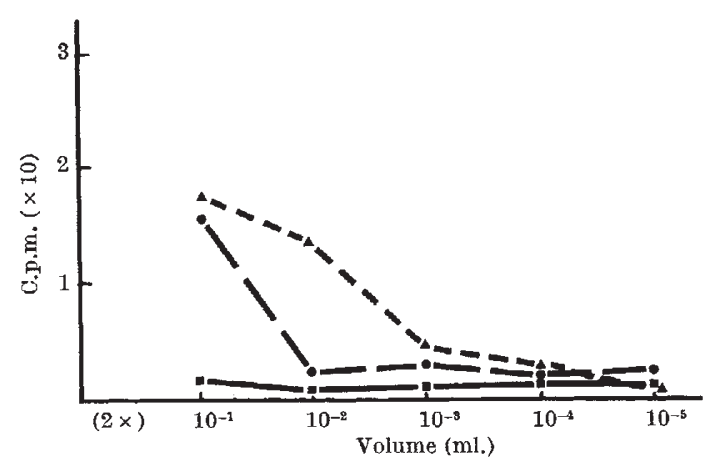

Fig. 9. Effects of three anti-immunoglobulin antisera, showing some stimulation at higher antibody concentrations of anti-IgG and anti-IgA. (A) Anti-IgG; ( ) anti-IgA; (D) anti-IgM. 
experimental conditions and can stimulate in another. This may be due to unknown factors in the culture technique or characteristics of the antisera. If the latter, then at least two classes of antibodies with differing activities may be present, one of which has a blocking action and the other a stimulatory effect. Which activity prevailed would depend on the relative proportion of the antibody classes in any one antiserum. Alternatively, one class of antibody may be present which has the capacity to exert different functions depending on the conditions of contact with the lymphocytes. An important condition may well be the concentration of molecules in relation to surface receptor sites. The alternative functions could then be explained by the surface changes that are caused when a critical concentration is reached.

M. J. S. was supported by a grant from the National Health and Medical Research Council, Canberra, Australia.

Received April 4 ; revised July 17, 1968.

1 Nowell, P. C., Cancer Res., 20, 462 (1960).

${ }^{2}$ Robbins, J. H., Science, 146, 1648 (1964).

${ }^{3}$ Bach, F., and Hirschhorn, K., Seminars in Haematol., 2 (1), 68 (1965).

${ }^{4}$ The Lymphocyte in Immunology and Haemopoiesis (edit. by Yoffey, J. M.) (Arnold, 1967).

${ }^{5}$ Coulson, A. S., and Chalmers, D. G., Nature, 209, 378 (1966).

- Yam, L. T., Castoldi, G. L., and Mitus, W. J., J. Lab. Clin. Med., 70, 699 (1967). ? Moorhead, J. F., Connolly, J. J., and McFarland, W., J. Immunol., 99, 413
(1967).
${ }^{8}$ Wilson, D. B., J.Exp. Zool.,162, 161 (1966).

${ }^{\circ}$ Simons, M. J., and Fitzgerald, M. G., Proc. Austral. Soc. Med. Res., 2, 121 (1967).

${ }^{10}$ Gräsbeck, R., Nordman, C. T., and de la Chapelle, A., Lancet, i, 385 (1963)

${ }^{11}$ Caron, G. A., and Sarkany, I., Nature, 210, 314 (1966).

12 Marshall, W. H., and Mellman, S., Clin. Exp. Immunol., 1, 189 (1966).

${ }^{13}$ Pearmain, G., Lycette, R. R., and Fitzgerald, P. H., Lancet, i, 637 (1963).

14 Elves, M. W., and Israels, M. G. C., Brit. J. Haematol., 9, 406 (1963).

${ }^{15}$ Forsdyke, D. R., in The Biological Effects of Phytohaemagglutinin (edit. by Elves, M. W.), 115 (Robert Jones and Agnes Hunt Orthopaedic Hospita Management Committee, Oswestry, 1966).

${ }^{16}$ Abaza, H. M., and Woodruff, M. F. A., Revue fr. Etud. Clin. Biol., 11, 821 (1966).

${ }^{17}$ Byrd, W. J., Finley, W. H., Finley, S. U., and McLure, S., Lancet, i, 420 (1964).

${ }^{18}$ Spitz, M., Nature, 202, 902 (1964).

${ }^{19}$ Marshall, W. H., and Norins, L. C., Austral. J. Exp. Biol. Med., Sci., 43 $213(1965)$.

${ }^{20}$ Ling, N. R., Knight, S., Hardy, D., Stanworth, D. R., and Holt, P. J. L. in Anti-lymphocyte Serum, Ciba Foundation Study Group No. 29, 41 (1967).

${ }^{21}$ Woodruff, M. F. A., James, K., Anderson, N. F., and Reid, B. L., in Antilymphocyte Serum, Ciba Foundation Study Group No. 29, 57 (1967).

${ }^{22}$ Simons, M. J., Proc. A ustral. Soc. Med. Res., 2, 121 (1967).

${ }^{23}$ Greaves, M. F., Roitt, I. M., Zamir, R., and Carnaghan, R. B. A., Lancet, ii, 1317 (1967).

${ }^{24}$ Sell, S., and Gell, P. G. H., J. Exp. Med.,122, 923 (1965).

${ }^{25}$ Adinolfi, M., Gardner, B., Gianelli, F., and McGuire, M., Experientia, 23, $271(1967)$.

${ }^{26}$ Gell, P. G. H., in Anti-lymphocyte Serum, Ciba Foundation Study Group No. 29, 50 (1967).

${ }^{27}$ Copperman, R., and Morton, H. E., Proc. Soc. Exp. Biol. and Med., 123, 790 (1966).

${ }^{28}$ Olson, G. B., South, M. A., and (Good, R. A., Nature, 214, 695 (1967).

\section{Glyceraldehyde 3-Phosphate Dehydrogenase from Pig Muscle}

by

\section{J. IEUAN HARRIS \\ RICHARD N. PERHAM*}

MRC Laboratory of Molecular Biology, Hills Road, Cambridge

\begin{abstract}
A unique amino-acid sequence for the polypeptide chain of pig muscle glyceraldehyde 3-phosphate dehydrogenase has been derived. This shows that the active enzyme contains four polypeptide chains of identical sequence and that there is a striking homology between the sequence of this enzyme and that of the same enzyme from lobster -a phylogenetically distant organism.
\end{abstract}

KNOWLEDGE of the structure of an enzyme is an essential prerequisite for the understanding of its mechanism of action. At present this can only be achieved in three dimensions by X-ray crystallography, for which the determination of the amino-acid sequence of the protein is highly desirable if not essential.

One of the key enzymes of glycolysis in almost all organisms is glyceraldehyde 3-phosphate dehydrogenase (GPDH), an enzyme which has been the subject of much interest for many years ${ }^{1,2}$. It has been shown that GPDH from a number of sources (for example, mammals and yeast) consists of four probably identical polypeptide chains - each of molecular weight 36,000-forming a tetrameric structure of molecular weight 144,000 (refs. 3-5). Evidence in agreement with these proposals has been obtained by X-ray diffraction analysis of crystals of the enzyme from lobster muscle ${ }^{6}$. These X-ray crystallographic studies are being continued and, partly to facilitate this study, the complete amino-acid sequence of the protein subunit in the lobster muscle enzyme has been estab. lished ${ }^{7}$. This proved that the lobster enzyme is composed of four identical polypeptide chains, each of 333 aminoacid residues, corresponding to a molecular weight of 36,003 . We wish to present here the complete amino-acid sequence of the enzyme from pig skeletal muscle, a poly. peptide chain of 332 residues, four of which chains comprise the active enzyme molecule.

* Also Department of Biochemistry, Tennis Court Road, Cambridge.
Comparison of the amino-acid sequences of the enzyme from pig and lobster muscle is of interest both from the point of view of three-dimensional structure and mode of action and of protein evolution. Preliminary accounts of some aspects of this work have already been published ${ }^{8,9}$.

GPDH was prepared from pig skeletal muscle ${ }^{10}$. $S$-carboxymethylation with $\left[2-{ }^{14} \mathrm{C}\right]$-iodoacetic acid and tryptic digestion were carried out as previously described ${ }^{4}$. The tryptic peptides were fractionated by gel-filtration on 'Sephadex $G-25$ ' and ' $G-50$ ', followed by suitable combinations of high voltage electrophoresis and chromatography on paper. Other peptide fragments were obtained by tryptic digestion of $S-\left[2{ }^{14} \mathrm{C}\right]$-carboxymethylated protein in which the lysine residues had been sub. stituted by reaction with either $S$-ethyltrifluorothioacetate $^{7,11}$ or maleic anhydride ${ }^{12}$. Digestion of these lysine-blocked derivatives was thus limited to the ten arginyl bonds in the protein and the resulting peptide fragments were obtained in pure form as their $N$-maleyl (MA) or $N$-trifluoroacetyl (TFA) derivatives by suitable combinations of gel-filtration, ehromatography on DEAEcellulose and paper electrophoresis. In this way twelve unique peptides which together account for all the aminoacid residues (see ref. 4) in the protein chain of pig GPDH were obtained (Table 1). As expected, ten of these peptides contained C-terminal arginine and another-the $\mathrm{C}$-terminal peptide in the protein chain-contained C-terminal glutamic acid. The presence of an additional peptide 